\title{
FRAGMENTAÇÃO E ENTRELAÇAMENTO EM SALA DE AULA: A CRÍTICA DE UMA EXPERIÊNCIA NO ESTÁGIO DE ENSINO DE LÍNGUA PORTUGUESA
}

\author{
FRAGMENTATION AND ENTANGLEMENT IN THE CLASSROOM: \\ THE CRITICISM OF AN EXPERIENCE \\ IN THE PORTUGUESE LANGUAGE TEACHING PRACTICE
}

\author{
Bianca Franchini da Silva | Lattes| revisaobifranchini@gmail.com \\ Universidade Federal de Santa Catarina \\ Samara Laís Zimermann | Lattes | samarazimermann@gmail.com \\ Universidade Federal de Santa Catarina
}

Resumo: Destinamo-nos, neste artigo, a expor, ainda que minimamente, o tensionamento entre duas práticas de ensino de Língua Portuguesa que permearam a nossa experiência de Estágio de Ensino de Língua Portuguesa e Literatura II, obrigatório para o Curso de Letras-Português, da Universidade Federal de Santa Catarina (UFSC). Nele, defrontamo-nos com um ensino fragmentado e normativo, e, para nossa prática, voltamo-nos ao ensino integral e reflexivo, ancorado à concepção dialógica e sociointeracionista da linguagem e à concepção pedagógica histórico-crítica, presente nas políticas públicas atuais voltadas para educação. Para isso, antes de expormos (crítica e reflexivamente) essa confrontação, revisitamos, brevemente, a história das teorias educacionais e os documentos pedagógicos parametrizadores e as propostas pedagógicas que estão em vigência. Em seguida, sintetizamos concepções com as quais nossa atuação se ancorou: de língua sociointeracionista - gêneros do discurso - (BAKHTIN [VOLOSHINOV], 1995 [1929]; BAKHTIN, 2011 [1979]) e instrumento de mediação simbólica (VIGOTSKY, 1991); de prática pedagógica do ensino de Língua Portuguesa sob quatro eixos - escrita, leitura, gramática e oralidade - (ANTUNES, 2003); e de sujeito ativo no processo de aprendizagem (VIGOTSKY, 1991). Com o tensionamento exposto, concluímos que a reflexão feita, mesmo em sua limitação no que tange ao curto tempo de realização, colabora para as discussões no campo da Linguística Aplicada (LA) que dizem respeito às diferentes práticas de ensino de Língua Portuguesa que concorrem e coocorrem em sala de aula e, por vezes, algumas delas distanciam-se das tendências atuais de ensino, associando-se a aspectos da concepção tradicional e tecnicista.

Palavras-chave: Linguística Aplicada. Ensino Língua Portuguesa. Estágio Língua Portuguesa. Sociointeracionismo. 
Abstract: In this article, we aim to expose, albeit minimally, the tension between two Portuguese Language teaching practices that permeated our experience of Teaching Portuguese Language and Literature II, mandatory for the Portuguese Language Undergraduate Program, from Universidade Federal de Santa Catarina (UFSC). In teaching practice, we were faced with a splintered and normative teaching, and, for our own practice, we turn to integral and reflective teaching, anchored in the dialogical and social interactionist conception of language and in the historical-critical pedagogical conception, present in current public policies for education. Before exposing (critically and reflexively) this confrontation, we briefly revisit the history of educational theories, the parameterizing pedagogical documents, and the pedagogical proposals that are valid nowadays. Then, we synthesized the concepts in which our performance was anchored: social interactionist language - discourse genres - (BAKHTIN [VOLOSHINOV], 1995 [1929]; BAKHTIN, 2011 [1979]) and symbolic mediation instrument (VIGOTSKY, 1991); the pedagogical practice of teaching the Portuguese language under four axes writing, reading, grammar and oral language - (ANTUNES, 2003); and an active subject in the learning process (VIGOTSKY, 1991). Within this scenario just exposed, we concluded that the reflection made, even in its limitation regarding the short time of implementation, adds to the discussions in the field of Applied Linguistics concerning the different Portuguese Language teaching practices that compete and co-occur in the classroom, which sometimes distance themselves from current teaching trends, thus associating themselves with aspects of the traditional and technicist conception of language teaching.

Keywords: Applied Linguistics. Teaching Portuguese Language. Portuguese Language Practice. Sociointeractionism.

\section{INTRODUÇÃO}

O insucesso escolar ainda é um dos grandes desafios da escola na atualidade, e as aulas de Língua Portuguesa não fogem muito desse preceito, uma vez que, segundo Antunes (2003, p. 19), ainda existe “[...] a persistência de uma prática pedagógica reducionista do estudo da palavra e da frase descontextualizadas". Ao nos depararmos, em nosso Estágio de Ensino de Língua Portuguesa e Literatura II, com uma prática pedagógica como essa - que ponderamos e refletimos neste artigo como sendo frag- 
mentada e reducionista -, vimo-nos desafiadas ao deslocamento a uma prática de ensino mais integral e reflexiva, à luz da teoria sociointeracionista. É a partir dessa realidade experienciada em período de estágio supervisionado (realizado no ano de 2018, obrigatório para a formação em Letras-Português, pela Universidade Federal de Santa Catarina - UFSC), que colocamos, aqui, em tensionamento esses dois exemplos de práticas de ensino, de modo a retratar que práticas de ensino consideradas, por vezes, superadas ou antiquadas ainda estão presentes em sala de aula e que existem discussões importantes a serem realizadas sobre o fazer pedagógico.

Brevemente, é válido introduzir que o contexto da nossa atuação se deu em uma instituição de Florianópolis, em que foi realizado o trabalho com duas turmas relativas ao $2^{\circ}$ ano do Ensino Médio, com a peculiaridade de serem, ao mesmo tempo, cursos técnicos integrados. Isto é, os estudantes cursam o currículo integral do Ensino Médio juntamente com a formação técnica específica a uma área de conhecimento, com duração - a depender de cada curso - de três a quatro anos.

O nosso projeto de estágio foi subdividido em etapas, nas quais, de maneira sintetizada: (i) buscamos conhecer o funcionamento da instituição e as peculiaridades das atividades e das relações dos alunos, já que acreditamos que o ambiente escolar precisa ser reconhecido criticamente; (ii) observamos a prática docente da professora regente; (iii) planejamos as aulas, considerando algumas práticas sociais das duas turmas e não nos distanciando de nossa base teórico-metodológica; (iv) ministramos os encontros; e, por fim, (v) produzimos um relatório sobre esse processo que durou um semestre letivo. Neste artigo, detemo-nos à confrontação, basicamente, entre duas dessas etapas: a prática da professora regente, exibindo alguns exemplos que verificamos na etapa de observação; e a nossa prática pedagógica - esta que, aliás, foi planejada considerando o conteúdo programático da professora regente. Isto posto, importa ressaltar que abordamos marcos importantes da história da educação no Brasil para expor o processo de criação das tendências educacionais atuais e as concepções pedagógicas majoritárias nos documentos parametrizadores e nas propostas governamentais. Porém, cabe o adendo de que em nenhum momento da história uma prática pedagógica foi absoluta, sendo o campo da educação sempre permeado por embates. Assim, o tensionamento que abordamos neste artigo, delineado pelos quatro eixos de Antunes (2003) - escrita, oralidade, gramática e leitura - e sob a égide da teoria sociointeracionista, endereçada aos escritos do Círculo de Bakhtin, expõe a pluralidade de métodos e de práticas que encontramos em sala de aula e suas peculiaridades. 
Nesse interim, aliás, ainda que com toda essa confrontação feita, evidenciamos que estamos cientes de que nosso período de atuação foi relativamente curto. Enquanto que a professora regente tem contrato efetivo de 40 horas na instituição, atuando em diversas turmas, de diferentes níveis, nós a observamos somente por dez horas/aulas (com exceção de atividades observadas extraclasse) e atuamos em sala de aula por 48 horas/aulas, para cada uma das duas turmas. A prática que observamos da professora e a nossa prática situam-se, sobretudo: em um dado momento histórico; em uma dada circunstância; e em condições de uma dada situação social.

Em relação à segmentação deste texto, abordaremos, na seção 2, o contexto histórico das concepções pedagógicas no Brasil e, ao mesmo tempo, os documentos parametrizadores governamentais vigentes, com o intuito de entendermos as tendências pedagógicas atuais e os tensionamentos históricos das práticas de educação. Após isso, na seção 3, evocaremos nossa base teórica que nos deu suporte durante todo nosso Estágio de Docência, o que se mostra decisivo, já que é a maneira com que nos posicionamos perante toda história das teorias educacionais e com que buscamos traçar um planejamento coerente com os movimentos recentes da educação brasileira. Posteriormente, é na seção 4 que será evidenciado o tensionamento entre uma prática de ensino de língua tecnicista, que, por vezes, é considerada antiga e até superada, e uma prática pedagógica que segue as tendências atuais de educação e busca o ensino de língua integral e historicamente situado. Com esse tensionamento feito, cremos que este artigo possa contribuir para as discussões atuais de Linguística Aplicada (LA) sobre práticas do ensino de Língua Portuguesa.

\section{QUESTÕES HISTÓRICAS: A EDUCAÇÃO E O ENSINO DE LÍNGUA}

As teorias educacionais e o saber pedagógico sofreram modificações ao longo dos anos, em uma caminhada histórica que continua ressignificando-os. Contudo, isso não se refletiu diretamente nas práticas pedagógicas. Assim, nesta seção, apresentamos, brevemente, (i) alguns marcos históricos educacionais e seus desdobramentos, (ii) quais tendências educacionais são atuais e (iii) os documentos norteadores de ensino que estão em vigor. Nossa intenção, nesta seção, é demonstrar que: apesar de toda a mudança história e das teorias e práticas de ensino majoritárias na atualidade, diferentes práticas e teorias ainda concorrem e coocorrem nas instituições. Com isso, nas seções subsequentes, abordaremos o tensionamento entre as práticas discutidas em nosso estágio de docência sob a ótica da história da educação (além da concepção de ensino de língua, colocada adiante). 
Isto posto, de acordo com os estudos de Saviani (2005), a primeira concepção pedagógica no Brasil foi desenvolvida com os jesuítas (1549), intitulada como tradicional religiosa e foi majoritária por, aproximadamente, 200 anos. Com as reformas pombalinas, começaram a ser inseridas disciplinas avulsas que eram consideradas leigas, no entanto, o ensino ainda era muito relacionado à religião. Depois da metade do século XIX, esse método de ensino converteu-se, progressivamente, ao método intuitivo, que manteve sua força até 1920, quando o movimento da Escola Nova ganhou visibilidade. Foi nesse período que a concepção pedagógica renovadora passou a ser reconhecida através da criação da Associação Brasileira de Educação (ABE), da realização das Conferências Nacionais de Educação e da publicação do "Manifesto dos Pioneiros da Educação Nova”, em 1932 (SAVIANI, 2005). Essa nova concepção foi desenvolvida com o intuito de abandonar o autoritarismo e promover a preparação dos indivíduos para questões individuais e sociais.

No entanto, já na década de 1930, a Escola Nova encontrou forte resistência, uma vez que as tendências tradicionais ainda estavam arraigadas na educação brasileira. Ganham força, nesse mesmo momento, questionamentos sobre o ideal educativo para a pedagogia brasileira por parte de estudiosos da área. Contudo, vale ressaltar que, mesmo com a difusão da Escola Nova, grande parte dos cursos de formação de professores e das instituições de ensino permaneceram sob o domínio do pensamento católico e de concepções pedagógicas anteriores a ela.

Com a criação do Instituto Nacional de Estudos Pedagógicos (INEP) ${ }^{1}$, em 1938, o incentivo à renovação pedagógica cresceu, e, a partir de 1945, a concepção humanista moderna assumiu uma posição importante no Brasil. Isso pode ser comprovado pela elaboração da Lei de Diretrizes e Bases da Educação Nacional (LDB), em 1947, que foi construída por educadores que defendiam novas ideias e a renovação da escola (BRASIL, 1996).

Assim, seguindo a corrente e para não perder sua força, por um lado, a escola católica renovou seus métodos de ensino sem deixar de lado a doutrina religiosa. Por outro lado, no mesmo período, houve a criação dos colégios de aplicação das Universidades Federais, e, cada vez mais, crescia a renovação dos modelos de ensino laico e apartado da igreja (SAVIANI, 2005).

No final da década 60, essas mudanças diminuíram de intensidade, e começou a ser instaurado, no Brasil, um ensino com tendência tecnicista. Essa concepção pedagógica produtivista ganhou visibilidade e força devido ao golpe militar, e “[...] a educação passou a ser entendida como [...] algo decisivo do ponto de vista do desenvolvimento

\footnotetext{
${ }^{1}$ Cabe ressaltar que o INEP foi criado, de início, para orientar políticas públicas de educação. No entanto,
} atualmente, assume, principalmente, o monitoramento e a avaliação da Educação no Brasil. 
econômico, um bem de produção, portanto" (SAVIANI, 2005, p. 19). Assim, na década de 70, a educação, para o governo, começou a ter um papel relevante na formação para o trabalho e, consequentemente, para o sistema capitalista. Com a chegada dos anos 80 , essa concepção pedagógica sofreu algumas alterações, já que a educação passou a definir a empregabilidade dos indivíduos. Mais do que um ensino tecnicista, a educação passou a ser um investimento individual na luta pelos empregos.

Ao longo dos anos, foram ganhando força outras concepções pedagógicas que problematizavam o que estava sendo feito, sendo intituladas, então, de pedagogias contra-hegemônicas (SAVIANI, 2005), as quais, segundo Saviani (2005, p. 35), eram

[...] aquelas orientações que não apenas não conseguiram se tornar dominantes, mas que buscam intencional e sistematicamente colocar a educação a serviço das forças que lutam para transformar a ordem vigente visando a instaurar uma nova forma de sociedade. Situam-se nesse âmbito as pedagogias socialista, libertária, comunista, libertadora, históricocrítica.

Assim, é possível dizer que a transição para Escola Nova vem acontecendo desde o final do século XX, e que, anteriormente, as concepções pedagógicas consistiam em práticas de ensino, muitas vezes, descontextualizadas e fragmentadas. Isto posto, podemos identificar, a partir deste breve histórico, que existiram e existem diversas teorias educacionais. Na grande área de ensino de língua, isso também acontece (SAVIANI, 2005).

Vamos evidenciar, neste artigo, que, no nosso período de estágio, experienciamos essas teorias coocorrendo e concorrendo, métodos e práticas que são consideradas de momentos históricos distintos coexistindo. Nesse aspecto, cabe elucidar que assumimos uma concepção contra-hegêmonica histórico-crítica que hoje é considerada, por muitos estudiosos do ensino de língua, uma das fortes concepções pedagógicas da atualidade. No entanto, conforme iremos expor ainda neste texto, a professora regente ainda mantinha um método de ensino de língua muito atrelado ao tecnicista (que abordamos na breve linha do tempo traçada acima). Uma prática que, por vezes, é considerada antiquada.

Acreditamos ser necessário, ainda, além de olhar para a história das teorias educacionais, debruçarmo-nos sob os principais documentos parametrizadores governamentais e nas propostas pedagógicas em vigor hoje no Brasil e em Santa Catarina. Dessa maneira, cabe ressaltar que atuar em uma Instituição Pública de Ensino Fundamental e de Ensino Médio, como fizemos em nosso Estágio de Docência, significa seguir documentos desde o Plano Nacional de Educação (PNE) (BRASIL, 2014) e a Base 
Nacional Comum Curricular (BNCC) (BRASIL, 2017; BRASIL, 2018), que têm alcance nacional, até a Proposta Curricular de Santa Catarina e o Projeto Político da Instituição ${ }^{2}$. Dessa maneira, é fundamental descrevermos, ainda nesta seção, mesmo que sumariamente, o que são esses escritos e por onde caminhamos para delimitarmos nossa prática docente.

O PNE (BRASIL, 2014) é uma lei aprovada para o decênio 2014-2024 constituída por dez diretrizes, 20 metas e 254 estratégias, as quais têm a finalidade de orientar políticas públicas relacionadas à educação em todos os níveis do ensino. Amplamente discutido, levando mais de dois anos na câmara dos deputados e seis meses no Senado Federal para ser aprovado, esse é um documento político e estratégico que visa assegurar maior equidade e qualidade no ensino para todos. Ou seja, ele trata, sobretudo, de direitos voltados para educação em um sentido amplo.

Diante disso, visando ao melhor entendimento das diretrizes específicas de ensino de Língua Portuguesa no Brasil, conduzimo-nos à BNCC. Esta, que é um plano de escolarização para cada etapa do Ensino Fundamental e do Ensino Médio, foi construída nos últimos anos e tem pretensão de ser "implementada" no ano de 2020. Vale lembrar que ela se propõe a definir quais conhecimentos são essenciais para serem abordados na escola, ou seja, definir eixos e objetivos de aprendizagem. Divide-se, ainda, em dois períodos escolares, o Ensino Fundamental ( 1 e 2) e o Ensino Médio, e, dentro dessas fases, a BNCC é subdividida em áreas do conhecimento e não em disciplinas em si. Esse documento, como um todo, visa à formação integral do sujeito, de forma a levar em consideração as experiências do estudante a fim de promover, de aprofundar e de alargar conhecimentos. Nós nos detemos à grande área de linguagens e, mais especificamente, em Língua Portuguesa, o que nos dois períodos escolares contam com os mesmos eixos norteadores: leitura, produção de textos, oralidade (escuta e produção oral) e análise linguística/semiótica. Cabe ressaltar que esses eixos são, também, base para nosso fundamento teórico que evidenciaremos mais adiante. Assim, a BNCC direciona para o componente Língua Portuguesa a seguinte atribuição:

[...] proporcionar aos estudantes experiências que contribuam para a ampliação dos letramentos, de forma a possibilitar a participação significativa e crítica nas diversas práticas sociais permeadas/constituídas pela oralidade, pela escrita e por outras linguagens (BRASIL, 2018).

\footnotetext{
${ }^{2}$ Diferentemente do habitual Projeto Político Pedagógico (PPP), a instituição em que atuamos optou pela grafia Projeto Político da Instituição (PPI).
} 
Além dos documentos que regulamentam e que parametrizam a estrutura educacional no Brasil, há, em nível estadual, um documento orientador, a Proposta Curricular de Santa Catarina (PCSC) (SANTA CATARINA, 2014), publicada pela primeira vez na década de 1980. Com ela, Santa Catarina tornou-se um dos estados pioneiros no Brasil a elaborar um documento com diretrizes curriculares com o intuito de orientar o planejamento dos currículos das redes estaduais e municipais. A sua última atualização foi publicada em 2019, uma vez que a primeira proposta já precisava de ajustes e não correspondia aos avanços tecnológicos e às questões relativas à diversidade social. Assim como a BNCC, a PCSC não trabalha com as disciplinas isoladas, mas acredita no agrupamento das áreas de conhecimento buscando um processo formativo menos fragmentado. Nesses escritos, intenta-se, também, a formação do sujeito através de diferentes instrumentos culturais que possibilitem o entendimento da diversidade social, levando-se em consideração o seu tempo histórico.

Assim, após a leitura desses documentos (sem mencionar outros importantes ${ }^{3}$ ) que norteiam as práticas pedagógicas, cabe ressaltar que também nos detemos ao documento que tem como função direcionar os passos da própria escola. Na nossa atuação, fizemos uso desse documento, conforme descreveremos mais adiante, para conhecer as práticas da escola.

Com base nessas considerações, a próxima seção diz respeito a esse aprofundamento nas teorias de ensino da língua, definindo, dessa maneira, nossa base teórico-metodológica.

\section{QUESTÕES TEÓRICAS: LÍNGUA, GÊNEROS DO DISCURSO E SUJEITOS}

Para desenvolvermos o projeto de docência, foi fundamental ter uma base teórica firme que sustentasse nossos passos, pois "[...] nada do que se realiza em sala de aula deixa de estar dependente de um conjunto de princípios teóricos" (ANTUNES, 2003, p. 39). Desse modo, tendo a consciência de que uma verdadeira aprendizagem se faz pela pura relação horizontal, para, assim, ocorrer o desenvolvimento de um pensamento reflexivo e este ser levado para fora de sala de aula, a ancoragem teórica com que convergimos tem uma concepção de língua como atividade interacional ou sociointeracionista (BAKHTIN [VOLOSHINOV], 1995 [1929]) ou, ainda, língua/signo como instrumento de mediação simbólica (VIGOTSKY, 1991). Uma língua que se atualiza em situações de atuação social e através de práticas discursivas (ANTUNES, 2003). Além disso, apoiamo-nos à concepção de sujeito corpóreo, social, responsivo/respondente, responsável/ singular, consciente, incompleto e protagonista (que refrata), assim, que é ativo no processo de aprendizagem (VIGOTSKY, 1991).

\footnotetext{
3 Ainda há outros documentos importantes que norteiam as instituições de Ensino Médio, como os Parâmetros Curriculares Nacionais (PCNs) (BRASIL, 1988) e as Orientações Curriculares Nacionais para o Ensino Médio (BRASIL, 2006), todos alinhados com as propostas atuais mencionadas.
} 
Com isso posto, a partir da concepção de língua que, pela enunciação e pelas enunciações, “[...] é constituída [...] pelo fenômeno social da interação verbal” (BAKHTIN [VOLOSHINOV], 1995 [1929], p. 123), afluímos com as ideias de que a atividade humana é heterogênea e de que nós falamos “[...] apenas através de determinados gêneros do discurso". Isto é, “[...] todos os nossos enunciados possuem formas relativamente estáveis e típicas de construção do todo" (BAKHTIN, 2011 [1979], p. 282, grifos do autor). Portanto, as interações sociais são diversas (abrangendo desde suas mediações pela linguagem verbal até as demais modalidades semióticas) e, à vista disso, cada esfera sociodiscursiva (ou campo da atividade humana) postula e efetua os gêneros discursivos.

Para Bakhtin (2011 [1979]), os gêneros do discurso (i) são orientadores do falante no processo discursivo e do interlocutor no cálculo do acabamento do enunciado, (ii) são unidades de comunicação discursiva diferentes, mas que possuem características comuns que as determinam e lhes dão acabamento (dentre essas, as formas típicas de gênero) e (iii) são transmissores de determinada visão de mundo, uma vez que experimentamos o mundo através deles. À medida que confluímos com seus dizeres, ao atuarmos com os gêneros do discurso dentro de sala de aula, trabalhamos, também, com as mudanças da vida social que os perpassam. Nesse contexto, a proposta de se trabalhar com os gêneros do discurso possibilita que se explore o texto enquanto enunciado a partir das características de cada gênero, da sua função social, da autoria, do leitor (público-alvo), dos já-ditos, da reação-resposta dos interlocutores e da circulação nas esferas do discurso (BAKHTIN, 2011 [1979]). Dessa forma, explorar os gêneros do discurso em sala de aula é praticar os usos sociais da linguagem.

Contudo, a atividade do ensino de língua se mostra complexa e ampla, já que precisa ser produtiva e relevante tanto individualmente quanto socialmente. Para a prática pedagógica do ensino de língua, longe de ser mecanicista ou de um receituário (ANTUNES, 2003), seguimos, como base, os quatros eixos (ou princípios) de Antunes (2003) para aula de português: a escrita, a leitura, a gramática e a oralidade. Para colocarmos o dialogismo, os gêneros do discurso (BAKHTIN, 2011 [1979]) e esses eixos (ANTUNES, 2003) em prática, nossa base teórica se faz, ainda, somada a uma concepção de abordagem histórico-cultural de educação, ou seja, que configura a língua como o instrumento psicológico de medição simbólica (VIGOTSKY, 1991). Nesse aspecto, a aprendizagem move o desenvolvimento, e o sujeito, nesse viés e para nós, desenvolve-se em um ambiente sociocultural. Por isso, as suas interações sociais, o meio em que vive e a bagagem cultural que possui devem, imprescindivelmente, ser levadas em consideração, pois constituem a formação integral desse sujeito. 
Se consideramos que o sujeito está em constante movimento, estamos em confluência com a teoria sociointeracionista e entendemos que esse sujeito se constrói e se reconstrói ao longo de um tempo histórico, de uma realidade social e cultural. Assim, os fundamentos ontológicos de uma concepção histórico-social de formação dos seres humanos ${ }^{4}$ consideram, para a dinâmica essencial do trabalho (este que é a atividade responsável pela qual o homem transforma a natura e a si próprio), a dialética entre apropriação e objetivação (DUARTE, 1998). Essa dialética é “[...] característica ontológica ineliminável da prática social humana $[. .].[\mathrm{e}]$ constitui $[. .$.$] o necessário ponto de partida para a re-$ flexão epistemológica numa perspectiva histórico-social” (DUARTE, 1998, p. 109). Isso se explica pelo fato de que, tanto pela apropriação de conhecimentos já existentes quanto pela produção de conhecimentos novos, a relação entre sujeito e objeto precisa ser considerada, pela análise epistemológica, sob um plano de historicidade. Assim, à medida que a objetivação e a apropriação não se realizam sem as objetivações passadas existentes de outros seres humanos e que a "[...] apropriação das objetivações do gênero humano é uma necessidade do próprio processo de formação da individualidade" (DUARTE, 1998, p. 110), a apropriação da cultura pelos indivíduos é, dessa forma, um processo educativo. É nesse ponto que Leontiev (1978 apud DUARTE, 1998), a partir de algumas características principais, analisa o processo de apropriação cultural e revela que esse processo: (i) é sempre ativo, pois o indivíduo precisa realizar uma atividade que "[... ] reproduza os traços essenciais da atividade acumulada no objeto" (LEONTIEV, 1978 apud DUARTE, 1998, p. 110), o que evidencia que não necessariamente o indivíduo precisa produzir o objeto, mas sim utilizá-lo; (ii) é cumulativo e reproduz, no indivíduo, aptidões e funções historicamente formadas pelos humanos, o que se caracteriza como um processo que faz a mediação entre "[...] o processo histórico de formação do gênero humano e o processo de formação de cada indivíduo enquanto ser humano" (DUARTE, 1998, p. 110); e (iii) é educativo, pois é um processo sempre mediado pelas relações humanas, através da comunicação entre eles.

A partir desse último ponto, mesmo que se possa pensar diretamente na esfera escolar, é válido salientar que a apropriação cultural, o processo de conhecimento e o processo de formação do indivíduo se fazem em todas as esferas sociais. Ainda assim, a abordagem histórico-social do processo de conhecimento mostra-se fundamental para se pensar o pro-

\footnotetext{
${ }^{4}$ A concepção histórico-social de formação está para além de um modelo epistemológico biologizante, como é o caso do modelo interacionista-construtivista (que tem sua expressão maior na obra de Piaget).
} 
cesso educativo em sala de aula, uma vez que este é o ato de produzir humanidade em cada indivíduo singular (seja de forma direta, seja de forma intencional), sendo essa humanidade produzida histórica e coletivamente pelos seres humanos (SAVIANI apud DUARTE, 1998). A produção do ato educativo se caracteriza por ser direta em relação a dois pontos: a relação direta entre educador e educando; e o resultado direto do trabalho educativo é a humanização do indivíduo. Essa humanidade resulta, como já mencionado, na atividade social objetivadora que os homens detêm, não existindo, pois, uma essência humana que seja independente da atividade histórica dos seres humanos, assim como não há uma humanidade pronta e dada aos indivíduos singulares, já que esses a produzem novamente.

É com esse cenário que a comunidade escolar tem o dever de reconhecer a íntima relação entre práticas educacionais e cultura e, por consequência, de criar esforços para contemplar as diversidades histórica, social e cultural dos sujeitos em seu método de ensino, uma vez que a “[...] aprendizagem escolar nunca parte do zero" (VIGOTSKY, 1988, p. 109). E, no que diz respeito ao ensino de língua, “[... ] o papel da escola deve ser o de garantir ao aluno o acesso à escrita e aos discursos que se organizam a partir dela” (BRITTO, 1997 apud BRITTO, 2012, p. 65). A ação pedagógica que a educação linguística precisa incorporar é conduzir o estudante à percepção da língua e da linguagem como “[...] fenômenos históricos complexos, a compreender seu funcionamento, usos e formas, bem como saber usá-la com propriedade nas modalidades oral e escrita, em especial para estudar e aprender viver sua subjetividade" (BRITTO, 2012, p. 84).

Assim, contrariamente ao pensamento retrógrado de que ao professor (sendo um detentor de todo o conhecimento, a autoridade tanto intelectual quanto moral) fica incumbido o trabalho de sistematizar conteúdos, conceitos e informações e de depositá-los em seus alunos, como se estes fossem vazios, em uma relação simbolizada pela verticalidade, entendemos que aprendizagem somente ocorre na relação horizontal. Ou seja, uma relação que conduz à formação do indivíduo reflexivo e que leva seus aprendizados para além dos muros da escola. Prezamos pela formação do ser social, do indivíduo distante daquele que somente memoriza e que executa ações repetitivas para aquele que trabalha, constrói, questiona, critica. Assim, a formação dos alunos, com a atividade de estudo e com suas criações, tem como resultado a possibilidade de esses sujeitos manifestarem suas personalidades (DAVIDOV, 1999).

De modo a convergir com uma abordagem voltada à perspectiva crítica de currículo, lembramos que, para Paulo Freire (MIZUKAMI, 2013), o conceito de ensino e o de aprendizagem se ampliam, e a educação “[...] deverá procurar a superação da relação opressor-oprimido” (MIZUKAMI, 2013, p. 99). O interesse dessa abordagem é provocar 
a consciência crítica e libertadora da pessoa que aprende. Para que isso ocorra, é necessário que haja o diálogo entre professor e aluno, pois a "[...] dialogicidade é a essência dessa educação” (MIZUKAMI, 2013, p. 100), em uma relação horizontal.

Com isso posto, partimos para a seção das questões metodológicas postas em tensionamento, que envolveram a prática da professora regente, anotadas no período observação (uma das etapas do processo do estágio de docência), e a nossa prática.

\section{QUESTÕES METODOLÓGICAS: DA OBSERVAÇÃO AO PROJETO}

Esta seção se destina a aventar exemplos possíveis de confrontação entre duas práticas de ensino de Língua Portuguesa: a que observamos da professora regente - assim como alguns pontos de seu planejamento; e a que atuamos no período de estágio destinado a nós. Ainda que a história do ensino de língua evidencie um deslocamento de uma prática tradicional para uma prática de interação, verificamos (mesmo de modo breve nesse curto período de estágio) que a prática encontra marcas de um ensino de língua fragmentado e verticalizado.

Antes, é preciso, na primeira subseção, confrontar os documentos parametrizadores e os documentos que regem a instituição. Em seguida, contextualizamos pontos fundamentais do período de estágio e, com isso, seguimos para as práticas em tensão.

\subsection{HISTÓRIA E PRÁTICA}

O Ensino Médio, segundo a BNCC (BRASIL, 2018), tem como foco duas palavras-chave: aprofundar e alargar. Podemos pensar, então, que o ensino não deve ser dividido em blocos, ele é contínuo: completa-se e reconfigura-se com o passar dos anos. Buscamos, nesse aspecto, intensificar e não ignorar os conhecimentos prévios dos estudantes.

Com isso em mente, durante a primeira etapa do nosso estágio, fizemos o reconhecimento da instituição de ensino em que iríamos ter nossa experiência de docência. Dessa maneira, analisamos o PPI que faz parte do Plano de Desenvolvimento Institucional (PDI) para poder estruturar nossos planejamentos. Cabe ressaltar que esses documentos são considerados, pela instituição de ensino, instrumentos teórico-metodológicos que orientam seus passos. Neles, visualizamos que a instituição adota: uma gestão democrática e participativa; e uma concepção histórico-crítica, entendendo a educação como prática social - posição que é refletida nos documentos governamentais em vigência e que, também, associa-se à nossa visão de ensino e aprendizagem (já manifestada neste artigo). 
Além do PDI, são feitos, por essa instituição de ensino, Projetos Pedagógicos dos Cursos (PPCs) que são documentos específicos para cada nível de ensino (ou seja, para cada curso técnico), os quais, dentre tantos outros detalhes técnicos-funcionais ${ }^{5}$, evidenciam a estruturação de cada um dos cursos técnicos integrados (com as especificidades curriculares das fases técnicas, mas, também, com competências, habilidades, bases tecnológicas e bibliografia das áreas presentes na BNCC). Neles, no que diz respeito especificamente ao ensino de Língua Portuguesa, constatamos a presença de trechos que mencionam a importância de se trabalhar com a intertextualidade e com a transversalidade temática, enfocando-se na valorização da diversidade de contextos histórico-sociais.

Assim, colocamos em destaque que esses documentos (descritos sinteticamente nesta subseção): mostram-se alinhados com as mudanças mais recentes nas concepções-pedagógicas; e serviram-nos de apoio no planejamento de uma prática que almeja mais do que o trabalho com uma disciplina isolada, mas a promoção de uma educação contextualizada historicamente, considerando as diversidades individuais e as mudanças prescritas na atualidade.

No entanto, mesmo com todas as mudanças históricas de metodologias de ensino no país e com o alinhamento dos documentos nacionais, estaduais e da própria instituição, quando nos direcionamos para a sala de aula em período de estágio de docência, a realidade foi diferente da que imaginávamos, e é isso que nos propusemos a colocar em tensionamento: a prática da professora regente e a nossa prática, ambas mais detidamente colocadas nas subseções adiante.

\subsection{DA FRAGMENTAÇÃO AO ENTRELAÇAMENTO}

Para a elaboração de um projeto de estágio que siga pontos em conformidade com nossa base teórica-epistemológica sociointeracionista, é imprescindível que passemos por algumas etapas básicas. Dentre elas, é preciso conhecer pontos primordiais do funcionamento da instituição de ensino, contemplando, por exemplo, seu histórico, os cursos desenvolvidos, sua organização educacional (os documentos regentes são um exemplo) e estrutural, e, ainda, as relações dos estudantes, dos professores e de outros funcionários, observando-os dentro de sala de aula e em outros espaços da instituição. Essas etapas evidenciam que, se temos a pretensão de promover relacionamentos construtivos entre todos os envolvidos no processo educacional, nós enxergamos o ambiente escolar “[...]

\footnotetext{
${ }^{5}$ Os PPCs contêm, ainda, os dados gerais do curso, a justificativa (com relevância e pesquisa) de oferta do curso, seus objetivos, os requisitos de acesso, perfil profissional de conclusão (competências) e as unidades curriculares de cada fase do curso. Também, são expostas questões de infraestrutura que envolvem o curso, bem como explicações sobre certificação, avaliação e trancamento de curso.
} 
como local de aprendizagem que não se realiza solitariamente, pois comporta uma rede de elementos interdependentes de aspectos humanos e físicos [...] bem como de aspectos estruturais" (BORTOLOTTO et al., 2011, p. 20).

A etapa de observação da professora regente e dos alunos (que durou 10 horas/aula) foi o pontapé inicial para que verificássemos o desafio do qual estávamos diante. Nessa etapa, pudemos anotar pontos que se mostraram cruciais para nosso planejamento e para nossa atuação em aula: (i) soubemos que ficaríamos responsáveis por toda construção do projeto de docência para duas turmas de quartas fases de diferentes cursos técnicos integrados (relativas ao $2^{\circ}$ ano do Ensino Médio); (ii) conhecemos algumas práticas sociais dos alunos, suas relações com o conhecimento técnico dos cursos, com as aulas de Língua Portuguesa e notamos a predominância de alunos homens nas turmas e na instituição como um todo; (iii) anotamos pontos de planejamento e de prática da professora regente e os configuramos como sendo de caráter tecnicista (tradicional), com marcas de atuação ainda rígidas e verticalizadas - conforme colocaremos mais adiante em tensão, sobretudo, com a nossa prática mais reflexiva e interativa (como pretendemos) -; (iv) fomos avisadas de que precisaríamos, em nossas práticas, seguir, ao menos, o conteúdo programático já organizado pela professora regente (que seriam aulas para o trabalho com o tipo textual dissertação-expositiva e aulas para a escola literária Parnasianismo - nessa ordem e sem a preocupação de qualquer conexão entre eles); e, ainda, (v) estudamos o PPI e o PPC da instituição e apuramos seu caráter crítico, transversal, histórico e social (o que se mostrou contrário aos últimos dois pontos - (iii) e (iv) - mencionados).

Todo esse embate entre, de um lado, a atuação e o planejamento da professora, os conteúdos programáticos que ela destinou a nós (os quais caracterizamos como fragmentados entre si) e, de outro lado, a nossa base teórica, os documentos parametrizadores nacionais e estaduais e, ainda, os documentos da própria instituição nos fizeram construir um projeto desafiador que contemplasse nossos desejos, mas que não abandonasse a fragmentação que nos foi solicitada.

Ainda que não tivéssemos conseguido unir diretamente esses dois conteúdos, intentamos colocar em funcionamento, em cada um deles, o dialogismo, os gêneros dos discursos (BAKHTIN, 2011 [1979]), os principais eixos das aulas de Língua Portuguesa (ANTUNES, 2003), os ideais de sujeitos ativos e sócio-historicamente construídos e os pontos cruciais da observação (desse momento histórico; dessa circunstância; e dessa situação social). Assim, primeiramente, escolhemos o tema transversal mulher na ciência e na tecnologia para a produção do tipo textual dissertação-expositiva, justificando-se, 
principalmente, por se tratarem de turmas de cursos técnicos ligados à ciência. Esta, aliás, há muitos anos é considerada uma atuação estritamente realizada por homens, o que, durante séculos, submeteu as mulheres a lutas e a quebras de estereótipos (de gênero, de capacidade, de qualidades/competências, de direitos, de representação social, enfim), ainda em veemência na atualidade. Visando, então, à promoção de interações, de debates, de análises linguísticas e tornando o sujeito ativo no processo de aprendizagem, pudemos explorar a disparidade de gênero, a construção de estereótipos em diversos âmbitos, inclusive e sobretudo no das ciências exatas, e os posicionamentos contra atos notórios e sutis de discriminação. Evidenciamos, por exemplo, que a "[...] intimidação, [a] insegurança, [a] estigmatização, [a] segregação, [o] isolamento” (WELTER; GROSSI, 2018, p. 131) provocam o desinteresse das mulheres pelos estudos na escola e na universidade e, consequentemente, conduzem-nas às evasões escolar/universitária e tumultuam “[...] o processo de configuração e expressão identitária” (WELTER; GROSSI, 2018, p. 131).

Para o outro conteúdo delimitado a nós, ou seja, para trabalharmos com a escola literária parnasiana, utilizamos os memes, pois, através de sua linguagem e de seus recursos multissemióticos, colaborando para a divulgação de questões sócio-históricas, “[...] apresentam construção temática, propósito comunicativo e estilo, caracterizando-os como gêneros discursivos, e, por localizarem-se em ambientes digitais, mobilizam um conjunto de letramentos" (GONÇALVES; LIMA, 2017, p. 2). Em sua predominância, esse gênero circula nas redes sociais e mídias digitais com a característica humorística e conduz o leitor, em sua apreciação, a tornar-se o coautor (GONÇALVES; LIMA, 2017), uma vez que se constata que "[...] é necessário ativar um conjunto de estratégias cognitivas e metacognitivas para situar o gênero sociohistoricamente e recuperar-lhe o sentido" (GONÇALVES; LIMA, 2017, p. 2).

Antes de seguirmos para as próximas subseções, é importante colocar que, ainda que tivéssemos o mesmo planejamento de aulas, tínhamos a compreensão de que em cada turma todo esse esquema se daria de maneira flexível, de modo a contemplar as diversidades histórica, social e cultural de cada sujeito. Esse aspecto, por sinal, não visualizamos nas aulas da professora regente, justamente por revelar uma prática de relação verticalizada em sua atuação em aula. Ainda que receosa no início, a professora regente nos deu liberdade para prosseguirmos com nosso projeto, dando-nos auxílio sempre que precisávamos, assim como nossa orientadora.

Com essas ponderações feitas, podemos colocar em tensionamento/confrontação a prática da professora regente, exibindo alguns exemplos que verificamos na etapa de 
observação, e a nossa prática pedagógica, exemplificando nossas atividades e visões. Para isso, decidimos estruturar as próximas subseções de acordo com cada eixo (ANTUNES, 2003) da aula de Língua Portuguesa.

\subsection{ESCRITA: DA PERIFÉRICA À CONTEXTUALIZADA}

Ao iniciarmos pelo eixo da escrita, colocamos em evidência que, nas aulas da professora regente, observamos a execução de exercícios como sendo a única prática de escrita realizada pelos alunos, uma vez que, ao longo das aulas, muitos deles mal tocavam em seus materiais, pelo fato de as aulas serem expositivas, com entrega do conteúdo sintetizado em folhas impressas. Isso mostra "[...] a prática de uma escrita mecânica e periférica, centrada, inicialmente, nas habilidades motoras de produzir sinais gráficos e, mais adiante, na memorização pura e simples de regras” (ANTUNES, 2003, p. 26). Além disso, o maior trabalho de escrita estava destinado às aulas que fossem para o estudo da dissertação-expositiva.

Como entendemos que a escrita, assim como a leitura (que será descrita posteriormente), deve ocorrer em um trabalho continuado "[...] nas atividades de estudo, na preparação de intervenção e organização do que e como se pretende fazer e na avaliação do que se escreveu ou se falou" (BRITTO, 2012, p. 94, grifos nossos), priorizamos o trabalho de escrita a partir do processo de produção textual e de criação entendendo a dissertação-expositiva como o início para a produção de uma dissertação-argumentativa - tipos textuais presentes nas escolas e nos concursos públicos -, e esta segunda um importante meio de expressão e de posicionamento.

Contudo, para isso, foi imprescindível que fosse feita a recapitulação da distinção entre tipo textual e gênero textual, basicamente, a partir de Furlanetto (2002). Sob a perspectiva de um ensino sociointeracionista, à medida que entendemos que a escrita, "[...] na diversidade de seus usos, cumpre funções comunicativas socialmente específicas e relevantes" (ANTUNES, 2003, p. 47), ao nosso encargo, como docentes, fez parte do nosso projeto a elaboração de uma escrita escolar para um leitor específico, um destinatário. Ou seja, foi planejada a execução de uma revista digital, para que, neste gênero textual, pudesse ser possibilitado um fim social às dissertações escritas pelos alunos das duas turmas, não ficando seus textos somente como produtos de uma aula e encerrados nela. Logo, para desenvolver essa escrita de maneira a ter o que dizer e para quem dizer, suas produções se relacionaram com suas vivências e se destinaram a leitores dessa mesma comunidade escolar, interessados tanto pela temática quanto por exemplos de escrita e de estrutura do tipo textual dissertação-expositiva, para futuras práticas em provas de concursos públicos. 
Convergindo com a nossa visão didático-pedagógica, para o processo de escrita em si, priorizamos a seguinte ordem: prática de leitura, seguida de prática de análise linguística, seguida de prática de produção textual, passando-se para a prática de análise linguística e, assim, encaminhando-se para a reescritura (que seria a nova produção textual) (RODRIGUES; CERUTTI-RIZZATTI, 2011).

Em outras palavras, antes mesmo de realizar a escrita em si: partimos da leitura e da interpretação/discussão de diversos textos de diferentes gêneros textuais ${ }^{6}$ sobre a temática escolhida para a dissertação-expositiva; fizemos análises linguísticas desses gêneros, as quais se resumem em debates, atividades e reflexões sobre o assunto, a partir de construções dialogadas e de referenciais dos alunos (e não sendo confundidas com análises de cunho gramatical); e discutimos e estudamos a estrutura do tipo textual dissertação-expositiva.

Em relação à prática de análise linguística, é válido abrir um parêntese para evidenciar que esta não se configura como a concepção de somente verificação gramati$\mathrm{cal}^{7}$ e de sua finalidade no âmbito escolar, como já citado, mas sim a ampliação disso, ou seja, que inclui, "[...] reflexões sobre texto, discurso, heterogeneidade da linguagem, ou seja, reflexões sobre aspectos da linguagem nos/para os processos interacionais" (RODRIGUES; CERUTTI-RIZZATTI, 2011, p. 144). Essa análise linguística que antecedeu a escrita foi primordial, pois conseguimos “[...] surpreender, mesmo naquilo que o texto tem de regular e de estável, a novidade ou o jeito original de interpretar o que é dito [...] [não sendo mais] exercício mecânico, pura rotina didática, cujo sentido se esvazia” (ANTUNES, 2010, p. 215).

Após a primeira escrita, a segunda análise linguística deu-se em cima dos próprios textos dos alunos, analisando-os em seus acertos e em suas tentativas malsucedidas, o que é provadamente eficaz para que o aluno perceba onde falhou e como pode melhorar na próxima etapa. A possibilidade de os alunos relerem seus textos e visualizarem neles exemplos reais do que está em discussão e em pauta na aula foi uma maneira de enriquecer a reescrita, ressaltando que a construção do conhecimento provém de uma interação. Assim, foi o momento em que os alunos expuseram seus pontos de vista, argumentaram a favor ou contra uma ideia, propuseram soluções para um problema, dentre outras maneiras de posicionamento, acentuando a importância da reflexão, do pensamento autônomo, da participação e da criação.

\footnotetext{
${ }^{6}$ Excertos do livro 50 brasileiras incríveis para conhecer antes de crescer, de Débora Thomé; excertos do livro As cientistas: 50 mulheres que mudaram o mundo, de Rachel Ignotofsky; o artigo científico Machismo na EMC: verdade ou mito?, de Luiz O. Kohler e de Maria J. Ioshiura, produzido por alunos da Engenharia Mecânica da UFSC; o vídeo Por que mulheres ganham menos?, da Série Explicando, do Netflix; e três episódios (Cientistas brilhantes; Garotas gamers; e Empreendedorismo) da série documental da Samsung: Tech girls.

${ }^{7}$ A gramática trabalhada será explicada na próxima subseção.
} 
É dessa forma que, "[...] o propósito de trazer o texto para o centro da atividade pedagógica, pouco a pouco, nos faz enxergar a língua por parâmetros bem mais amplos e funcionais" (ANTUNES, 2010, p. 216). Isso se refletiu positivamente nas reescritas de todos os alunos que melhoraram profundamente seus textos, tanto de maneira contextual, explorando informações relevantes e concretas, quanto de maneira estrutural, sabendo criar uma linha de pensamento coerente e coesa. Cabe ressaltar também que entendemos a necessidade da reescrita como parte do processo de construção da escrita.

Abrimos um parêntese para mencionar que, se, por um lado, todo esse processo recebeu aprovação e apoio de nossa orientadora, por outro, a professora regente se mostrou relutante à temática escolhida e a algumas dessas etapas, sobretudo à etapa de reescrita. Contudo, ao fim desse processo, diante de resultados positivos seja pelas produções adequadas ao que se pretendia no sentido de estrutura e de temática, seja pelos debates em aula e pelos feedbacks positivos dos estudantes, a professora regente apontou sua satisfação em poder conduzir práticas parecidas com as nossas em suas aulas.

Fechado o parêntese, com essas ponderações, anotamos: a escrita que propusemos no projeto foi uma atividade interativa, que mais do que a função de ensinar regras de ortografia, é uma escrita que pressupõe uma parceria entre os sujeitos.

\subsection{GRAMÁTICA: DA TRADICIONAL AO ENSINO SOCIOINTERACIONISTA}

Nesta subseção, colocamos em evidência o eixo da gramática, o qual se mostrou ser o foco principal da professora regente nas aulas observadas (estudo das regências nominal e verbal e crase). $\mathrm{O}$ primeiro ponto a dar destaque é justamente a divisão ${ }^{8}$, nos planos da professora, entre aulas destinadas ao ensino da gramática e aulas destinadas ao ensino de literatura ou à produção textual. Percebe-se, nesse aspecto, a existente descontextualização do trabalho com a gramática dentro de sala de aula, refletindo-se, aliás, na maneira com que são expostos os pontos gramaticais, como, por exemplo, aulas excessivamente expositivas, com exibição de muitas frases soltas, sem interlocutores, isoladas e fora de qualquer contexto, ou seja, a gramática "[...] amorfa, [...] que é [...] desvinculada, portanto, dos usos reais da língua escrita ou falada na comunicação do dia a dia" (ANTUNES, 2003, p. 31).

Além disso, as recorrentes menções feitas pela professora aos alunos para que falassem "corretamente", que utilizassem "corretamente" as regras da língua, ou que não cometessem "os erros" comuns do dia a dia, por exemplo, evidenciam o que Antunes (2003, p. 31): primeiro, chama de gramática das "excentricidades", a qual somente observa os pontos de vista refinados da gramática e que estão, muitas vezes, por fora dos contextos mais previsíveis de uso da língua; segundo, mostra como sendo uma gramá-

\footnotetext{
${ }^{8}$ Daremos mais destaque a essa divisão no eixo leitura, exposto adiante.
} 
tica que é inflexível, de uma língua supostamente inalterável, “[... ] como se o processo de mudança das línguas fosse apenas um fato do passado, algo que já aconteceu e não acontece mais" (ANTUNES, 2003, p. 32); e, terceiro, evidencia como sendo, predominantemente, uma gramática prescritiva, que apenas se preocupa em marcar o "certo" e o "errado", não havendo importância no que se diz, como e quando se diz e se tem algo a dizer (ANTUNES, 2003).

A partir dessas colocações, é oportuno fazer uma alusão ao que Bakhtin (1988 [1975]) chama de língua/linguagem única, a qual, nas relações sociais, preserva e conserva as normas linguísticas através do que o autor chama de forças centrípetas. Dessa maneira, a língua/linguagem única, que é oposta ao discurso diversificado, representa uma categoria teórica que unifica e centraliza o plurilinguismo, colocando a este "[...] certas barreiras, assegurando certo maximum de compreensão mútua e centralizando-se na unidade real, embora relativa, da linguagem falada (habitual) e da literária 'correta' (BAKHTIN, 1988 [1975], p. 81, grifo do autor). Aliás, Geraldi (1991, p. 133) retoma essa concepção, dizendo que é uma língua tomada como “[...] 'pronta', 'acabada', cabendo a seus falantes não um papel ativo de produção de linguagem, mas um papel de apropriação do já pronto ou de correção de desvios”. Consegue-se atribuir isso, também, ao que Rodrigues (2014) denomina de 'ensino enciclopedístico', o qual é "[...] pronto e acabado” (RODRIGUES, 2014, p. 49). No caso, a disciplina de Língua Portuguesa seria fundamentada na “[...] prevalência do conhecimento conceitual e taxionômico sobre o praxiológico e procedimental” (RODRIGUES, 2014, p. 49).

Isso tudo revela que ainda é mantido um estudo gramatical reducionista. Ainda que sob o ponto de vista da língua enquanto interação, a gramática é tomada como “[...] conjunto de regras que especificam o funcionamento de uma língua” (ANTUNES, 2003, p. 85), e, por isso, a língua não existindo sem suas regras gramaticais, acredita-se que esta é composta por regras flexíveis e mutáveis, pois reflete questões sociais. A gramática precisa, então, trabalhar com os usos linguísticos e suas variações, uma vez que “[...] uma gramática de regras incondicionalmente rígidas foge à realidade com que a comunicação verbal ocorre" (ANTUNES, 2003, p. 91).

Nesse fluxo, quando questionados sobre a importância do trabalho com a gramática em sala de aula, os alunos manifestavam não abandonar o referencial normativo, estando estagnados a pensar em concepções dicotômicas, "próprio e impróprio, adequado e inadequado, forma culta e popular, registro formal e informal, língua padrão e não-padrão [...]" (BRITTO, 2012, p. 63, grifos do autor), e não dirigindo seus olhares à importância do conhecimento, mas sim a um querer demonstrar o "certo", declinando-os, mais uma vez, à “[...] educação voltada para satisfazer as demandas do mercado” (BRITTO, 2012, p. 65). 
Outro ponto regularmente presente nas aulas da professora regente foi a repetição de exemplos e o excesso de exercícios de múltipla escolha sobre os aspectos gramaticais estudados, os quais, por vezes, também se repetiam. Pode-se inferir que isso tinha como objetivo a memorização e a fixação de regras da gramática e da ortografia. Contudo, como já mencionado, “[...] não se aprende por exercícios, mas por práticas significativas” (POSSENTI, 1996, p. 47, grifos do autor). Isso mostra que o “[...] grande equívoco em torno do ensino de língua tem sido o de acreditar que, ensinando análise sintática, ensinando nomenclatura gramatical, conseguimos deixar os alunos suficientemente competentes para ler e escrever textos, conforme as diversificadas situações sociais” (ANTUNES, 2003, p. 46).

Em nosso projeto, de maneira contextualizada, funcional e relevante, o ensino da gramática não se deu descontextualizado. Estudar a gramática normativa, com exercícios de análise linguística, deu-se a partir do estudo com gêneros do discurso, uma vez que entendemos que "[...] o domínio efetivo e ativo de uma língua dispensa o domínio de uma metalinguagem técnica" (POSSENTI, 1996, p. 53-54).

Assim, a gramática foi trabalhada ponto a ponto, texto por texto, mas não foi colocada profundamente no diálogo em sala de aula, pois a enxergamos como “[...] elemento-parte-de-um-todo, elemento nem mais nem menos relevante que outros" (ANTUNES, 2010, p. 217). Revisamos cada texto, de cada aluno, mas, como seus textos não demonstraram precisar de intervenção mais criteriosa nesse aspecto, abrimos nosso horizonte e soubemos articular as questões gramaticais "[...] de forma que os sentidos criados resultam da conjunção de todos; por exemplo, a conjunção do léxico e da gramática; do léxico e do tipo textual; do textual e do pragmático" (ANTUNES, 2010, p. 217).

\subsection{LEITURA: DA COBRANÇA À COLABORAÇÃO}

Assim como a escrita, a leitura é, entre as mais diversas formas de exercícios intelectuais, “[...] a que pressupõe a ação metacognitiva mais aguda”, pois o sujeito “[...] investe tempo e esforço para pensar, realizando ação intelectual autocontrolada [...]” (BRITTO, 2012, p. 88). Contudo, nas aulas observadas, o trabalho com a leitura também se dava, mais firmemente, através da realização de exercícios com foco na gramática. Mas, fazendo remissão à literatura, torna-se possível fazer a ressalva de que, como já mencionado anteriormente, houve a separação entre o estudo da gramática e o estudo da literatura, com aulas estipuladas e restritas, o que poderia ser trabalhado em confluência. Outro ponto a ser destacado é o ensino da literatura e de sua história pautado na divisão em escolas literárias. Ainda que nos PPCs da Instituição estivessem colocadas essas escolas, a professora 
fez seus planos com aulas restritas para o ensino de naturalismo e realismo (que estavam previstos para as aulas posteriores à nossa observação), desvinculando-os de qualquer outro encontro ao longo do semestre. Como exemplo, aliás, citamos o próprio conteúdo programático que nos foi destinado no período de estágio: o tipo textual dissertação-expositiva e a escola literária parnasiana.

Ainda a respeito da literatura, por exemplo, ficando, aos alunos, incumbida a tarefa de ler obras, já selecionadas pela professora, dessas duas escolas literárias, para que fizessem seminários ${ }^{9}$ expondo essas obras e seus autores aos colegas, é possível refletir sobre alguns pontos. Primeiro, trabalhar escolas literárias, com foco em suas características textuais, datas importantes, resumo das obras e assim sucessivamente, configura-se como uma divisão em um “[... modelo que pouco contribui para a formação de leitores que acabam decorando características soltas (e muitas vezes impróprias) [...] sem ter lido livro algum” (RAMOS; CORSO, 2013, p. 23, grifo das autoras). Segundo, a atividade de leitura torna-se "[...] puramente escolar, sem gosto, sem prazer, convertida em momentos de treino, de avaliação, ou de oportunidade para possíveis 'cobranças'” (ANTUNES, 2003, p. 28 , grifo da autora). E, terceiro, a leitura é deixada como trabalho fora de sala de aula, não havendo a colaboração do docente, que pode explorá-la de maneira conjunta com seus alunos, interrogando-os sobre o texto, abrindo, assim, a possibilidade de eles poderem distinguir a realidade e a ficção, identificar elementos textuais persuasivos, interpretar o sentido figurado, inferir intencionalidades do autor e assim por diante (BRASIL, 1998).

Como já mencionado nos eixos anteriores, o trabalho com a leitura, no nosso projeto de docência, deu-se imbricado aos demais eixos, com leituras interpretativas e dialogadas com os alunos, para que estes, sujeitos ativos e com seus horizontes axiológicos, fossem interlocutores, interagindo para a construção de pontes dialógicas que propiciassem um ambiente de aprendizagem. Ou seja, foram feitas leituras colaborativas, as quais, através de uma postura nossa de questionar os alunos, possibilitou, a eles, enxergar/perceber/sentir que o prazer do texto não está “[...] em tentar reter o significante ou conter os signos no momento em que se faz a leitura, mas fazer com que os leitores se animem com a fuga” (RAMOS; CORSO, 2013, pp. 96-97), conduzindo-os a uma “[...] ampliação dos repertórios [...] [para] incorporar novas ideias, novos conceitos, novos dados, novas e diferentes informações acerca das coisas, das pessoas, dos acontecimentos, do mundo no geral" (ANTUNES, 2003, p. 70). Assim, o trabalho com um ou dois textos no tempo de aula torna-se muito mais enriquecedor.

\footnotetext{
9 Os seminários serão mais comentados no eixo oralidade.
} 
Ao trabalhar com o Parnasianismo e a leitura de alguns de seus poemas, utilizamos versos soltos de poemas dessa escola literária, para que os alunos os reconstruíssem (sem conhecer o poema original) visando não somente à abertura de possibilidades de construção (de acordo com as individualidades), mas de, nesse trabalho, possibilitar a verificação de características próprias dessa escola literária, sem que estas fossem apresentadas a eles como mais uma lista pronta. Outra atividade que exploramos foi com os “[...] posicionamentos argumentativos presentes nos memes” (GONÇALVES; LIMA, 2017, p. 2) como forma de conduzir os alunos a criarem sínteses a respeito dos "conhecimentos teóricos" (DAVIDOV, 1999, p. 2) - ou seja, das características trabalhadas sobre o Parnasianismo - e de se posicionarem a respeito deles. Com isso, aproximando a escola literária de suas realidades, trabalhando o sócio-histórico e, principalmente, o interacional desse gênero do discurso, verificamos, nessa forma de atuação, uma maneira de proporcionar aos alunos o acompanhamento da "[...] interligação do interno com o externo no conteúdo do material assimilado" (DAVIDOV, 1999, p. 3) e, através de uma atividade de estudo e com suas criações, fazer com que pudessem ter como resultado a manifestação de suas personalidades (DAVIDOV, 1999).

\subsection{ORALIDADE: DAS RESPOSTAS PRONTAS AO DIÁLOGO}

Conduzimo-nos, nesta subseção, a refletir sobre a oralidade em sala de aula retomando as ponderações sobre os seminários. Pode-se inferir que esse tipo de apresentação é caracterizado, em sua essência, como forma de palestra, não se estendendo a fala para o restante da turma, a não ser para perguntas (mas que, dificilmente, ocorrem), estando o apresentador somente atingido por um olhar avaliativo do professor.

Outros momentos em que os alunos praticaram a oralidade foram quando a professora regente pedia a eles que: lessem frases descontextualizadas nos slides, lessem (em coral) as preposições de cada verbo; repetissem "macetes" ou "rimas" sobre regras da gramática; respondessem quais alternativas eram as corretas nos exercícios; e, ainda, complementassem as frases inacabadas pela professora. Pode ser dado, como exemplo, quando a professora dizia “Quem precisa, precisa...?”, e os alunos respondiam “... de algo!”. Isso poderia ser mais um dos exemplos que Geraldi (1991, p. 156, grifos do autor) coloca ao argumentar como a esses diálogos em sala de aula "[...] só cabem respostas cristalizadas, prontas e acabadas”, em que as respostas dos alunos “[...] são para serem 'corrigidas' e não para serem expandidas [...]". 
Assim, pensando-se no eixo oralidade, à medida que “[...] não existem diferenças essenciais entre oralidade e escrita nem, muito menos, grandes oposições" (ANTUNES, 2003, p. 99), pois ambas servem à interação verbal, articulamos, em nosso projeto, a exploração de debates como “[...] uma forma democrática e crucial que permite discussões para levantar prós e contras, não apenas do texto literário mas de como este pode ser trabalhado, explorado, vivenciado" (RAMOS; CORSO, 2013, p. 41, grifos nossos). Assim, o diálogo com os alunos, seja para discussão da temática transversal mulher na ciência e na tecnologia, para expor dúvidas e complementos, para interagir e debater nas atividades em grupo, seja para realizar a leitura em voz alta de textos dessa temática e de poemas Parnasianos, foi essencial para o desenvolvimento do projeto.

Uma vez que, conforme verificado nas aulas observadas, os alunos não recebiam abertura para a fala e, no início de nossa atuação, eles se mostraram bastante receosos para dialogarem, mas, com o passar das aulas e das atividades propostas, sentiram-se mais à vontade e deixaram suas satisfações a respeito disso registradas em seus questionários.

A oralidade e os demais eixos (com as características que prezamos) mostraram-se fundamentais para o progresso da aprendizagem dos estudantes, que expuseram que as aulas de Língua Portuguesa se tornaram mais dinâmicas, interativas e, por isso, mais divertidas, atribuindo-as a encontros de intensos debates, de interações, de diálogos e, sobretudo, de usos sociais da língua.

\section{CONSIDERAÇÕES FINAIS}

Neste artigo, tivemos a intenção de mostrar como o ensino de língua é complexo e abarca diferentes práticas, fazendo o tensionamento entre duas delas: uma considerada fragmentada e tecnicista e outra mais reflexiva e integral. A todo momento, nestes escritos, frisamos nossa afluência à concepção dialógica e sociointeracionista da linguagem (à luz dos escritos do Círculo de Bakhtin) e à concepção histórico-crítica de ensino, ambas contemporâneas e inscritas nos documentos pedagógicos parametrizadores e nas propostas pedagógicas que estão em vigência, conforme retratamos minimante ao longo deste texto.

Certas de nosso posicionamento, contudo, em nosso Estágio de Ensino de Língua Portuguesa e Literatura II, realizado em 2018, defrontamo-nos com desafios nos quais acreditávamos terem sido superados devido a essas atuais concepções pedagógicas e teorias educacionais: verificamos, na atuação da professora regente, a presença de metodologias de ensino características de uma pedagogia tecnicista. Ainda que os documentos da 
própria instituição desvelassem sua consonância com as concepções vigentes na contemporaneidade, de modo a motivar uma reorganização de práticas fragmentadas de ensino, conforme Antunes (2003, pp. 19-20, grifos nossos), “[...] as experiências de renovação [...] ainda não ultrapassam o domínio de iniciativas assistemáticas, eventuais e isoladas".

Nesse interim, ressaltamos que, historicamente, as teorias educacionais têm mais ou menos força, mas elas não se apagam na sala de aula. Métodos de ensino considerados "antigos" ou até mesmo refutados por novas tendências ainda continuam sendo colocados em prática, conforme observamos em uma das etapas da nossa vivência de estágio, e que, por isso, práticas concorrem e coocorrem, não existindo prática absoluta em nenhum momento histórico.

Apesar da concorrência e coocorrência dessas práticas de ensino dentro de sala de aula e de termos consciência de que nosso período de atuação foi curto e restrito, lutamos, a partir de nossa base teórica-epistemológica, para promover a superação não somente da fragmentação em sala de aula, mas sim, efetivamente, do trabalho educativo com a essência humana abstrata e a existência empírica. A essência abstrata é recusada quando a humanidade e as forças essenciais humanas são concebidas enquanto cultura humana objetiva e socialmente existente, enquanto produto da atividade histórica dos seres humanos. Nossa proposta também superou a concepção de educação guiada pela existência empírica, na medida em que sua referência para a educação é a formação do indivíduo enquanto membro do gênero humano, assim o trabalho educativo valoriza o desenvolvimento do indivíduo para além dos limites impostos pela divisão social do trabalho.

Enfrentar os desafios da diversidade cultural e das individualidades dos seres é aceitar que a escola é um espaço que cruza (além das culturas) variados saberes e é um ambiente responsável por formar indivíduos capazes de criticar e de refletir dentro da sociedade, fazendo-os ir além dos referentes presentes em seus cotidianos, assumindo-os e ampliando-os, o que transforma esses indivíduos em sujeitos ativos na mudança de seus contextos.

Através deste artigo, intentamos possibilitar o tensionamento entre duas práticas, contribuindo, na nossa opinião, para os debates atuais em Linguística Aplicada (LA), no que se referem aos estudos sobre práticas do ensino de Língua Portuguesa em sala de aula.

\section{REFERÊNCIAS}

ANTUNES, I. Aula de Português: encontro e interação. São Paulo: Parábola, 2003.

ANTUNES, I. Análise de textos: fundamentos e práticas. São Paulo: Parábola editorial, 2010. 
BAKHTIN, M. Estética da criação verbal. Tradução do russo por Paulo Bezerra. São Paulo: Martins Fontes, 2011 [1979].

BAKHTIN, M. Questões de literatura e de estética: a teoria do romance. Tradução de A. F. Bernardini et al. São Paulo: Hucitec, 1988 [1975].

BAKHTIN, M. M. [VOLOSHINOV]. Marxismo e filosofia da linguagem: problemas fundamentais do método sociológico na ciência da linguagem. Tradução de Michel Lahud e Yara F. Vieira. São Paulo: Hucitec, 1995 [1929].

BRASIL. Base Nacional Comum Curricular: Educação Infantil e Ensino Fundamental. Brasília: MEC/Secretaria de Educação Básica, 2017.

BRASIL. Base Nacional Comum Curricular: Ensino Médio. Brasília: MEC/Secretaria de Educação Básica, 2018.

BRASIL. Ministério de Educação e Cultura. LDB - Lei no 9394/96, de 20 de dezembro de 1996. Estabelece as diretrizes e bases da Educação Nacional. Brasília: MEC, 1996. Disponível em: <http://portal.mec.gov.br/arquivos/pdf/ldb.pdf>. Acesso em: 20 abr. 2018.

BRASIL. Lei n.13.005, de 25 de junho de 2014. Aprova o Plano Nacional de Educação PNE e dá outras providências. Diário Oficial da União, Brasília, DF., 26 jun. 2014.

BRASIL. Parâmetros curriculares nacionais. Brasília: MEC/SEF, 1998. Disponível em: <http://portal.mec.gov.br/seb/arquivos/pdf/portugues.pdf>. Acesso em: ago. 2019.

BRASIL. Orientações curriculares para o ensino médio. Brasília: MEC, 2006. Disponível em: <http://portal.mec.gov.br/component/tags/tag/33672 >. Acesso em: jun. 2020.

BRITTO, L. P. L. Inquietudes e desacordos: a leitura além do óbvio. São Paulo: Mercado de Letras, 2012.

BORTOLOTTO, N; PELANDRÉ, N. L..; MONGUILHOTT, I. O. S.; DEBUS, E. S. D. Estágio supervisionado I e II. Florianópolis: LLV/CCE/UFSC, 2011. Disponível em: <http://nead.uesc.br/arquivos/Letras/estagio_supervisionado_1/letras_estagio_ supervisionado_I_II.pdf $>$. Acesso em: 27 mar. 2018.

CIENTISTAS brilhantes (ep.1). Tech Girls [Série]. Produtora: Samsung, 2018. (4 min 20 s), son., color. Disponível em: <https://www.facebook.com/SamsungBrasil/videos/techgirls-epis\%C3\%B3dio-1-cientistas-brilhantes/1774625442560167/> . Acesso em: 2018.

DAVIDOV, V. V. O que é a atividade de estudo. Revista Escola Inicial, n. 7, p. 1-9, 1999.

DUARTE, N. Relações entre ontologia e epistemologia e a reflexão filosófica sobre o trabalho educativo. Perspectiva, v. 16, n. 29, p. 99-116, 1998. 
EMPREENDEDORAS (ep.3). Tech Girls [Série]. Produtora: Samsung, 2018. (5 min 17 s), son., color. Disponível em: <https://www.facebook.com/SamsungBrasil/videos/ tech-girls-epis\%C3\%B3dio-3-empreendedoras/1790263444329700/>. Acesso em: 10 ago. 2018.

FURLANETTO, M. M. Produzindo textos: gêneros ou tipos? Perspectiva, Florianópolis, v. 20, n. 1, p.77-104, jan/jun 2002.

GAROTAS gamers (ep.2). Tech Girls [Série]. Produtora: Samsung, 2018. (4 min 45 s), son., color. Disponível em: <https://pt-br.facebook.com/SamsungBrasil/ videos/1786075421415169/>. Acesso em: 10 ago. 2018.

GERALDI, J. W. Portos de passagem. São Paulo: Martins Fontes, 1991.

GONÇALVES, C. J. S. L.; LIMA, A. M. P. A argumentação como proposta discursiva dos memes. Revista Tecnologias na Educação, v. 19, jul. 2017.

IGNOTOFSKY, R. As cientistas: 50 mulheres que mudaram o mundo. Tradução de Sônia Augusto. São Paulo: Blucher, 2017.

KOHLER, L. O.; IOSHIURA, M. J. Machismo na EMC: verdade ou mito? Florianópolis: NEPET-UFSC, 2017.

MIZUKAMI, M. G. N. Ensino: as abordagens do processo. São Paulo: EPU, 2013.

POR QUE mulheres ganham menos (Temporada 1, ep. 3). Explicando [Série]. Criação: Ezra Klein, Joe Posner. Los Gatos, Califórnia, EUA: Produtora Netflix, 2018. (19 min.), son., color.

POSSENTI, S. Por que (não) ensinar gramática na escola. São Paulo: Mercado de Letras, 1996.

RAMOS, T. R. O.; CORSO, G. K. Literatura e ensino I: $9^{\circ}$ período. Florianópolis: UFSC/ CCE/LLV, 2013.

RODRIGUES, R. H. Os gêneros do discurso nas aulas de Língua Portuguesa: (re) discutindo o tema. In: NASCIMENTO, E. L.; ROJO, R. (Orgs.). Gêneros de texto/ discurso e os desafios da contemporaneidade. São Paulo: Pontes, 2014.

RODRIGUES, R. H.; CERUTTI-RIZZATTI, M. E. Linguística Aplicada: ensino de língua materna. Florianópolis: LLV/CCE/UFSC, 2011.

SANTA CATARINA. Proposta curricular de Santa Catarina: formação integral na 
educação básica. Florianópolis: SED, 2014.

SAVIANI, D. As concepções pedagógicas da educação brasileira. Campinas: Histedbr, 2005. Disponível em: <http://www.histedbr.fe.unicamp.br/navegando/artigos_pdf/ Dermeval_Saviani_artigo.pdf $>$.Acesso em: 29 out. 2019.

THOMÉ. D. 50 brasileiras incríveis para conhecer antes de crescer. Rio de Janeiro: Galera Record, 2017.

VIGOTSKY, L. S. A formação social da mente. São Paulo: Martins Fontes Editora Ltda, 1991.

VIGOTSKY, L. S. Aprendizagem e desenvolvimento intelectual na idade escolar. In:

VIGOTSKY, L. S; LURIA, A. R.; LEONT'EV, A. N. Linguagem, desenvolvimento e aprendizagem. 5. ed. São Paulo: Icone: EDUSP, 1988.

WELTER, T.; GROSSI, M. P.É possível ensinar gênero na escola? Análise de experiências de formação em gênero, sexualidade e diversidades em Santa Catarina. Revista Linhas, Florianópolis, v. 19, n. 39, p. 123-145, jan./abr. 2018.

Submetido em: 08/01/2020

Aceito em: $13 / 04 / 2020$ 